\title{
Near miss maternal morbidity and maternal mortality at Kathmandu Medical College Teaching Hospital
}

\author{
Shrestha NS ${ }^{1}$, Saha $\mathbf{R}^{1}$, Karki $C^{2}$ \\ ${ }^{1}$ Assistant Professor, ${ }^{2}$ Head and Professor, Department of Obstetrics \& Gynaecology, Kathmandu Medical College, \\ Sinamangal, Nepal
}

\begin{abstract}
Background: Maternal mortality traditionally has been the indicator of maternal health all over the world. More recently review of the cases with near miss obstetric events has been found to be useful to investigate maternal mortality.

Cases of near- miss are those in which women present with potentially fatal complication during pregnancy, delivery or the puerperium, and survives merely by chance or by good hospital care.

Objectives: The objective of this study is to determine the prevalence and nature of near miss obstetric cases and maternal deaths at Kathmandu Medical College Teaching Hospital.

Material and methods: This was a descriptive study done for the period of 24 months (1 January 2008 to 31 December 2009). Cases of severe obstetric morbidity were identified during daily morning meetings. All the cases were followed during their hospital stay till their discharge or death. Five factor scoring system was used to identify the near miss cases from all the severe obstetric morbidity. For each case of maternal death, data were collected from records of maternal death audit.

Results: During the study period, 1562 women delivered at the institution and 36 women were identified as near-miss obstetrical cases. The prevalence of near miss case in this study was $2.3 \%$. Five maternal deaths occurred during this period, resulting in a ratio of maternal death of 324 maternal deaths per 100,000 live births. Of the five maternal deaths three were due to pregnancy complicated with hepatitis E infection, one each due to Eclampsia and amniotic fluid embolism. Fifteen cases of near miss were due to haemorrhage $(41.66 \%)$ and hypertensive disorder of the pregnancy was the cause in $10(27.77 \%)$. Dystocia was the cause in $1(2.77 \%)$ case and infections in $7(19.4 \%)$ cases. Rare causes like anaesthetic complications were the cause in one case and dilated cardiomyopathy was the cause in two cases. Conclusion: The major causes of near-miss cases were similar to the causes of maternal mortality of Nepal. Need for the development of an effective audit system for maternal care which includes both near-miss obstetric morbidity and mortality is felt.
\end{abstract}

Key words: Near-miss obstetric morbidity, Maternal mortality, Five factor scoring system

$\mathrm{M}$ aternal mortality traditionally has been the indicator of maternal health all over the World. More recently review of the cases with near miss obstetric events has been found to be useful complement to investigate maternal mortality ${ }^{1,2}$. The study of nearmiss cases has also been used to evaluate the quality of obstetrical care in an institute.

Cases of near- miss are those in which women present with potentially fatal complication during pregnancy, delivery or during the puerperium, and who survive merely by chance or by good hospital care ${ }^{3}$. Near- miss cases occur more often than maternal deaths and may generate more information because the woman herself can be a source of data $^{4,5}$.
In developing countries little attention has been given to the near-miss obstetrics events. The scenario is similar in Nepal. This probably is a result of the persistently high levels of maternal mortality that has overshadowed other severe obstetric complications. In Nepal maternal mortality ratio has decreased from 539 per 100,000 live birth in 1998 to 229 per 100,000 live birth in 2008$2009^{6}$. However this figure is still very high and needs to be reduced further. In depth study of the cases of near- miss will definitely play a vital role in identifying the deficiency as well as strengths in the provision of

Correspondence

Dr. Nira Singh Shrestha

Assistant Professor

Department of Obstetrics \& Gynaecology, KMCTH

E-mail: shresthanira11@gmail.com 
obstetrical services in developing countries, and will be useful in correcting and strengthening the obstetrical care hence further reducing maternal mortality ratio.

In order to provide insight into the quality of maternal care in Kathmandu Medical College Teaching Hospital (KMCTH) this study was conducted to determine the prevalence and nature of near- miss obstetric cases and maternal deaths.

\section{Materials and methods}

Place of study

The study was conducted in the department of Obstetrics and Gynaecology, KMCTH, Sinmangal, Kathmandu, which is a tertiary care centre and serves as a referral centre for other hospitals within and outside the Kathmandu valley. Total number of delivery in this hospital is approximately 1000 per year. On average 4-5 serious obstetrical cases are referred every month from other centres for better care.

\section{Definition of cases}

Near-miss events are defined as acute obstetric complications that immediately threatens a woman's survival but do not result in her death either by chance or because of hospital care she receives during pregnancy, labour or within 6 weeks after termination of pregnancy or delivery ${ }^{1}$. For identifying near-miss cases five-factor scoring system was used ${ }^{7}$. The five-factor scoring system has the specificity of $93.9 \%$. It comprises of Organ -system failure, ICU admission, transfusion $>3$ units, extended intubation ( $>12$ hour), and surgical intervention(hysterectomy, relaparotomy). These factors are given the score of 5, 4, 3, 2, and 1 respectively. A five factor scoring system can theoretically have score from 0 to 15 (no clinical factor present to all clinical factors present). The cut off point for near- miss case is a score of 8 or greater.

\section{Study design and identification of cases}

This was a descriptive study done for the period of 24 months between 1 January 2008 and 31 December 2009. Cases of severe obstetric morbidity were identified during daily morning meetings, where all the new admission in the last 24 hour and serious inpatient cases are discussed. All the cases were followed during their hospital stay till their discharge or death. Five factor scoring system was used to identify the near miss cases from all the severe obstetric morbidity.

For each case of near miss, data were collected on demographic characteristics including gestational age at the time of sustaining the near-miss morbidity, nature of obstetric complication(s), presence of organ-system dysfunction/failure, ICU admission, and timing of near- miss event with respect to admission. Information on maternal deaths and deliveries conducted during the study period were obtained from maternal mortality audit and the labour /delivery registers. For each case of maternal death, data were collected on the demographic characteristics including gestational age at the time of death and the underlying cause of death.

Data analysis

Data were entered into a computer database using Microsoft Excel spreadsheet and statistical analysis was performed. Results are presented as frequencies, percentages and descriptive statistics. The prevalence of near-miss cases is defined as the number of near-miss cases divided by the number of deliveries in the hospital. The frequencies of near-miss events are reported according to the clinical condition responsible, referral status of the patients and whether the complications were present upon arrival or occurred while on admission at the hospital. Maternal mortality ratio was calculated as the number of maternal deaths per 100,000 live births.

\section{Results}

During the twenty-four months of the study period, 1562 women delivered at the institution and 36 women were identified as near-miss obstetrical cases by five factor scoring system. The prevalence of near miss case in this study was $2.3 \%$. Five maternal deaths occurred during this period, resulting in a ratio of maternal death of 324 maternal deaths per 100,000 live births.

The demographic characteristics of the women classified as near miss were: median age 27 (18-35), 11 $(30.5 \%)$ women were nulliparous and majority of them were para 1-2. Seventy percent of the cases of near miss were unbooked at KMCTH. Prevalence of near miss was approximately similar in first trimester, third trimester and postpartum period and was less in second trimester.

Twenty five percent of the cases were referred from other hospitals in a critical state for ICU care. Fifty eight percent of the cases were critical on arrival to hospital. Near miss case per 1000 delivery was 23.04. Maternal death to near miss ratio was1:7.2.

Fifteen cases of near miss were due to haemorrhage $(41.66 \%)$ of which ten were due to ruptured ectopic pregnancy. One was due to complication of illegal second trimester abortion where uterus was perforated with foetal parts in uterine cavity with massive haemoperitoneum. One case of placenta previa with placenta accreta which was a referred from district hospital required caesarean hysterectomy for control of massive haemorrhage. Of the three postpartum haemorrhages $(\mathrm{PPH})$ two cases were severe secondary 
post partum haemorrhage following caesarean delivery for which hysterectomy was required to control the bleeding. Third case of PPH was a case of home delivery with retained placenta with severe PPH in shock.

Hypertensive disorder of the pregnancy was another important condition and accounted for $27.77 \%$ of the near miss cases. Of the hypertensive disorder 5 were eclampsia and 5 severe preeclampsia. Cases of eclampsia received magnesium sulphate as anticonvulsant and were monitored in ICU. Of the severe preeclampsia 1 case was complicated with HELLP, 2 cases were associated with SLE and acute on chronic renal failure, 2 cases of impending eclampsia following termination of pregnancy were monitored in ICU. Dystocia was the cause in 1 case (Ruptured uterus with hand prolapse). Of the 7 infection 3 were infective hepatitis resulting in organ/system failure, 2 were puerperal sepsis leading to septic shock. Pyogenic lung abscess with septic shock during second trimester of pregnancy was another cause of near miss due to infection. One was a case of acute pyelonephritis leading septic shock and ARDS which required ventilator support for a week. Other cases of near miss were 2 cases of postpartum cardiomyopathy and one case of anaesthesia induced acute liver failure (Table 3).

Regarding the presence of different factors according to five factor scoring system, ICU admission was the most common factor followed closely by organ system failure (Table 4). Total 26 cases suffered from organ system failure of which 7 cases had more than one organ/system failure. Vascular failure was commonest followed by coagulation failure (Table 5)

There were 5 maternal mortalities of which 3 were due to Infective hepatitis, one was due to massive cerebral haemorrhage following postpartum eclampsia, and one was due to amniotic fluid embolism during second stage of labour. Four of the five cases (3 cases of infective hepatitis and a case of postpartum eclampsia) were referred from other facility in terminal stage.

Table 1: Demographic characteristics of women with near-miss morbidity and maternal death

\begin{tabular}{|c|c|c|}
\hline & Near-miss cases & Maternal deaths \\
\hline & $n=36(\%)$ & $n=5(\%)$ \\
\hline \multicolumn{3}{|l|}{ Parity } \\
\hline 0 & $11(30.5)$ & $2(40)$ \\
\hline $1-2$ & $22(61)$ & $3(60)$ \\
\hline $3-4$ & $2(5.55)$ & \\
\hline$\geq 5$ & $1(2.77)$ & \\
\hline \multicolumn{3}{|l|}{ Booking status } \\
\hline Unbooked at KMCTH & $25(70)$ & $4(80)$ \\
\hline \multicolumn{3}{|l|}{ Gestational age (weeks) } \\
\hline$<13$ & $11(30.5)$ & \\
\hline $13-28$ & $6(16.66)$ & $2(40)$ \\
\hline$>28$ & $10(27.77)$ & $2(40)$ \\
\hline Postpartum & $9(25)$ & $1(20)$ \\
\hline
\end{tabular}

Table 2: Frequency and characteristics of near-miss cases and maternal death

\begin{tabular}{|l|c|}
\hline & Total \\
\hline Deliveries (n) & 1562 \\
\hline Live births (n) & 1543 \\
\hline cases Near-miss (n) & 36 \\
\hline Referred from other facility [n (\%)] & $9(25)$ \\
\hline On arrival [n (\%)] & $21(58)$ \\
\hline During hospitalization & $15(42)$ \\
\hline Near-miss cases per 1000 deliveries & 23.04 \\
\hline Maternal deaths (n) & 5 \\
\hline MMR/100,000 live birth & 324 \\
\hline Maternal death to near-miss ratio & $1: 7.2$ \\
\hline
\end{tabular}


Table 3: Diagnosis distribution of near- miss cases

\begin{tabular}{|l|c|}
\hline Disease & Near miss- n(\%) \\
\hline Haemorrhage & $\mathbf{1 5 ( 4 1 . 6 6 )}$ \\
\hline Early pregnancy & 11 \\
\hline Ectopic pregnancy & 1 \\
\hline Abortion & $\mathbf{4}$ \\
\hline Late pregnancy & 1 \\
\hline Placenta previa & 3 \\
\hline Postpartum haemorrhage & $\mathbf{1 0 ( 2 7 . 7 7 )}$ \\
\hline Hypertension & 5 \\
\hline Eclampsia & $\mathbf{1 ( 2 . 7 7 )}$ \\
\hline Severe preeclampsia & 1 \\
\hline Dystocia & $\mathbf{7 ( 1 9 . 4 )}$ \\
\hline Uterine rupture & 2 \\
\hline Infections & 3 \\
\hline Puerperal sepsis & 1 \\
\hline Infective hepatitis & 1 \\
\hline Pyogenic lung abscess & $\mathbf{3 ( 8 . 3 1 )}$ \\
\hline Urinary sepsis & 1 \\
\hline Others & 2 \\
\hline Anaesthetic complication & 1 \\
\hline Dilated cardiomyopathy & \\
\hline
\end{tabular}

Table 4: Frequency of different factors of near-miss cases

\begin{tabular}{|l|c|}
\hline Factors & Total \\
\hline Organ system failure & 26 \\
\hline ICU admission & 28 \\
\hline Transfusion $>3$ units & 24 \\
\hline Extended intubation & 7 \\
\hline Surgical intervention & 6 \\
\hline
\end{tabular}

Table 5: Frequencies of organ system failure in near-miss cases

\begin{tabular}{|l|c|}
\hline Type of organ-system failure & Total \\
\hline Renal failure & 5 \\
\hline Coagulation failure & 8 \\
\hline Cardiac failure & 3 \\
\hline Hepatic faiure & 5 \\
\hline Vascular failure & 14 \\
\hline
\end{tabular}

\section{Discussion}

The prevalence of near miss case in this study was $2.3 \%$. Range of prevalance of near miss cases varied between $0.4 \%-8 \%$ in a systematic review of maternal morbidity and mortality done by $\mathrm{WHO}^{8}$. This wide variation in range was seen due to the difference in the criteria used for the identification of the near miss cases and the place of study. Rates were higher in resource poor setting area and whenever the organ-system based criteria was used. Prevalence was very high (1-25\%) in certain African studies 9 . Ratio of mortality to near miss morbidity in this study was $1: 7.2$. This ratio is similar to those of African country where the range is 1: $5-12^{10-13}$. In European studies it is $1: 117-223^{14}$. These large disparities may be due to difference in diagnostic criteria used to identify the near miss cases.

This study shows the leading cause of maternal mortality was infective hepatitis which is in agreement with 
the study done at $\mathrm{TUTH}^{15}$ which has shown infective hepatitis as the leading cause of maternal mortality in recent years in an institute. However haemorrhage, hypertensive disorder of pregnancy, and complication of abortion are still the leading cause of maternal mortality in $\mathrm{Nepal}^{6}$.

Pattern of near miss morbidity were different than that of maternal mortality in this study. The reason being high prevalence of hepatitis E infection in and around the city of Kathmandu valley which has high mortality especially during pregnancy. The pattern of near-miss in this study were similar to the findings of a study conducted by the Nepal Society of Obstetricians and Gynecologists in the year 2006 in six different medical institutions ${ }^{16}$. The findings were similar also to the findings in many other studies ${ }^{9,10}$. This finding means in depth analysis of these near miss cases will complement to investigation of maternal mortality. Majority of the women with near-miss morbidity arrived at the hospital in critical condition and more than two third of the near miss cases were not booked at KMCTH which reflects the delay in seeking health care and delay in timely referral.

\section{Conclusion}

The major causes of near-miss cases were similar to the causes of maternal mortality of Nepal. Lessons can be learned from cases of near-miss which can serve as a useful tool in reducing maternal mortality ratio. Need for development of an effective audit system for maternal care which includes both near-miss obstetric morbidity and mortality is felt.

\section{Acknowledgements}

I am thankful to our patients without whom this study would not have been possible; I am also thankful to all the faculty members and staffs of department of Obstetrics \& Gynaecology of the KMCTH for their help and support to complete this study.

\section{References}

1. Ronsmans C, Filippi V. Reviewing severe maternal morbidity: learning from survivors from life-threatening complications. In Beyond the Numbers: Reviewing Deaths and Complications to Make Pregnancy Safer. Geneva: World Health Organization; 2004. P.103-24.

2. Pattinson RC, Buchmann E, Mantel G, Schoon M, Rees H. Can enquiries into severe acute maternal morbidity act as a surrogate for maternal death enquiries? BJOG. 2003;110:889-93.

3. Souza JP, Cecatti JG, Parpinelli MA, Serruya SJ, Amaral E. Appropriate criteria for identification of near-miss maternal morbidity in tertiary care facilities: A cross sectional study. BMC Pregnancy and Childbirth. 2007;7:10.1186.

4. Stones W, Lim W, Al-Azzawi F, Kelly M. An investigation of maternal morbidity with identification of life-threatening 'near miss' episodes. Health Trends. 1991;23:13-5.

5. Pattinson RC, Hall M. Near misses: a useful adjunct to maternal death inquiries. $\mathrm{Br}$ Med Bull 2003;67:231-43.

6. Nepal maternal mortality and morbidity study 2008/09 - Summary of preliminary findings. Nepal: United Kingdom Department for International Development(DFID), Government of Nepal, United States Agency for International Development (USAID);2010.

7. Geller S.E, Rosenberg D, Cox S,Brown M,Simonson L, Kilpatrick S. A scoring system identified near-miss maternal morbidity during pregnancy. J Clin Epidemiol 2004;57:716-20.

8. Lale Say, Robert C Pattinson, Metin Gülmezoglu A. WHO systematic review of maternal morbidity and mortality: the prevalence of severe acute maternal morbidity $\backslash$ (near-miss). Reproductive Health 2004;1: 1186.

9. Filippi V, Ronsmans C, Gohou V, Goufodji S, Lardi M, Sahel A et al. Maternity wards or emergency obstetric rooms? Incidence of nearmiss events in African Hospitals. Acta Obstet Gynecol Scand. 2005; 84(1):11-6.

10. Olufemi T Oladapo, Adewale O Sule-Odu, AdetolaOOlatunji,OlusojiJDaniel."Near-miss" obstetric events and maternal deaths in Sagamu, Nigeria: a retrospective study. Reproductive Health. 2005; 2:9doi:10.1186/1742-4755-2-9.

11. Filippi V, Alihonou E, Mukantaganda S, Graham WJ, Ronsmans C. Near misses: maternal morbidity and mortality. Lancet. 1998;351:145- 46.

12. Prual A, Huguet D, Gabin O, Rabe G :Severe obstetric morbidity of the third trimester, delivery and early puerperium in Niamey (Niger). Afr J Reprod Health. 1998;2:10-9.

13. Sivalingam $N$, Looi $\mathrm{K}$ :Clinical experience with management of 'near- miss' cases in obstetrics. Med J Malaysia. 1999; 54:496-503.

14. Waterstone M, Bewley S, Wolfe C. Incidence and predictors of severe obstetric morbidity: case-control study. BMJ.2001;322:1089-94.

15. Rana A, Pradhan N, Manandher B, Bista KD, Gurung G, Amatya A: Maternal mortality over the last decade: a changing pattern of death due to alarming rise in hepatitis in the latter five-year period. J Obstet Gynecol Res.2009; 35(2):243-51.

16. Pradhan P. Maternal Intensive Care: Near-Miss mortality in Obstetrics. NJOG. 2008;3(1):1-2. 